\title{
Planejamento e organização da competição esportiva pedagógica para crianças e adolescentes: um exemplo no basquetebol
}

\author{
Planning and organization of pedagogical sports competition for children and adolescents: \\ an example on basketball
}

DOI: http://dx.doi.org/10.36453/2318-5104.2018.v16.n1.p259

\section{Felipe Canan ${ }^{1}$}

Universidade Estadual de Maringá (UEM)

${ }^{1}$ Aluno do Programa de Pós-Graduação Associado em Educação Física UEM/UEL

\section{RESUMO}

A competição esportiva para crianças e adolescentes carece de adaptações pedagógicas que, acima do resultado, contribuam para formação esportiva e humana. O objetivo deste estudo foi sistematizar uma experiência relativa a uma competição pedagógica de basquetebol. Foi adotada uma sistematização de experiências discutida à luz de Siedentop (1987) e Freire (2011). Como resultados, a competição adotou organização, regulamento e adaptações de regras que buscaram contribuir para geração de inclusão, competência e autonomia dos jogadores, em relação ao basquetebol, consoante o modelo/proposta dos autores citados. Finalmente, a avaliação positiva por parte dos participantes e a constatação de que apresenta proximidades com pressupostos de importantes autores da Pedagogia do Esporte tornam a competição sistematizada como uma boa experiência a ser compartilhada em busca de contribuir para a formação dos pares.

Palavras-chave: Ensino; Treinamento; Jogos esportivos coletivos; Fair play.

\section{ABSTRACT}

The sport competition for children and adolescents needs pedagogical adjustments that, above the result, contribute to sportive and human formation. The objective was to report an experience about a pedagogical basketball competition. Methodology: systematization of experiences discussed in the light of Siedentop (1987) and Freire (2011). As a results, the competition adopted organization, statute and adaptations of rules that sought to contribute to the generation of inclusion, competence and autonomy of players, in relation to basketball, according to the model/proposal of the cited authors. Finally, the positive evaluation by the participants and the finding that it is close to the assumptions of important authors of Sports Pedagogy credit the systematized competition as a good experience to be shared in order to contribute to the formation of peers.

Keywords: Teaching; Training; Collective sports games; Fair Play. 


\section{INTRODUÇÃO}

No processo de ensino-aprendizagem-treinamento (EAT) esportivo para crianças e adolescentes sempre acabam existindo dúvidas entre os limites do que seria o rendimento, a participação, a educação e a formação. É nessa seara que as discussões referentes à área da "Pedagogia do Esporte" acabam se inserindo, buscando identificar/oferecer meios pedagógicos de tratamento do esporte para tal público-alvo.

Como ensinar/treinar e competir de maneira a contribuir para a formação integral do praticante e não reproduzir a sistemática de treinamento e competição do alto rendimento esportivo é uma questão discutida por esta área de conhecimento (FREIRE, 2011; MONTAGNER, 2011; REVERDITO; SCAGLIA; MONTAGNER, 2013; SIEDENTOP, 1987; SANTANA, 2008). Não se trata necessariamente de utilizar o esporte como uma ferramenta educacional, mas sim (ou também) de se ensinar/treinar o esporte e competir adequadamente em cada faixa etária e em cada contexto. Mas como se ensinar/treinar uma prática que é, por sua própria natureza, competitiva, sem exacerbar a competição e gerar exclusão dos praticantes que se encontram menos preparados em cada momento do processo?

Primeiramente, nessa ótica, deve-se compreender que negar a competição ao público infanto-juvenil significa negar a própria prática do esporte, ao menos quando compreendido em seu sentido estrito, relativo às modalidades competitivas regradas internacionalmente (SIEDENTOP, 1987; SANTANA, 2008). Ao se considerar que este afigura-se como uma atividade historicamente construída e praticada pela humanidade, negá-lo a crianças e jovens significaria negar-lhes o acesso à própria cultura.

Valorizar a competição não significa buscar a vitória a qualquer preço, mas sim demonstrar compromisso em relação a ela, o que significa respeitar todos os envolvidos, que esperam que cada competidor dê o melhor de si. Como coloca Santana (2008), a competição é, antes de tudo, um ato de cooperação.

Nesse sentido, estabelecer a formação esportiva e não o resultado competitivo como o objetivo do processo de EAT para crianças e adolescentes, como colocam, por exemplo, Siedentop (1987), Santana (2008), Freire (2011), Montagner (2011) e Reverdito, Scaglia e Montagner (2013), não significa ignorar a competição ou não preparar-se e esforçar-se para vencê-la. Ela pode não ser o objetivo principal do processo por parte do treinador, mas sempre deverá ser (e comumente é) um elemento motivador para os praticantes, servindo também como um dos elementos de formação.

Não sendo adotada como um fim em si mesma, mas sim como um dos elementos do processo de formação esportiva, a competição automaticamente é despida da hipercompetitividade e da exclusão, abrindo margem para processos pedagógicos, tanto em relação à preparação para a mesma quanto à sua própria organização.

Dessa forma, a competição "formativa" ou "pedagógica" deve ser adaptada às condições das crianças e adolescentes praticantes e organizada para que todos possam participar efetivamente. Isto não ocorre com a simples mudança de nomenclatura de "competição" para "festival", ou a adoção de procedimentos como a ausência de tabela de classificação ou a premiação a todos os participantes, independentemente do resultado. Negar o resultado significa não dar um parâmetro para o próprio praticante sobre a qualidade de sua prática, além de desvalorizar aqueles que melhor se prepararam para tal (não seria esta uma forma de exclusão?). Por mais infantis que sejam os praticantes (à exceção de faixas etárias muito tenras, como, por exemplo, até os 7 ou 8 anos de idade aproximadamente), eles comumente compreendem o processo e sabem reconhecer a vitória, a derrota e o mérito ou não em receber a premiação (SANTANA, 2008).

Ao mesmo tempo, tornar uma competição mais pedagógica não diz respeito a modificar-se a lógica interna $^{1}$ de cada modalidade esportiva, mas sim a lógica externa ${ }^{2}$. Nas obras organizadas por Montagner (2011) e Reverdito, Scaglia e Montagner (2013), por exemplo, encontram-se relatos de várias possibilidades de

\footnotetext{
${ }^{1}$ Em linhas gerais, a lógica interna diz respeito às características de determinada prática corporal, que permitem identificá-la enquanto tal, diferenciando-a de outras (PARLEBAS, 2001). A dinâmica encontrada em um jogo de basquetebol, por exemplo, relativa às ações possíveis aos jogadores e aos objetivos do jogo (fazer/impedir a cesta) caracteriza a lógica interna do que internacionalmente se conhece e reconhece como "basquetebol".

${ }^{2}$ A ideia de lógica externa permite que, por exemplo, tanto uma final de campeonato mundial quanto um jogo disputado em uma aula de educação física escolar ou em momentos de lazer sejam identificados como "basquetebol", mas desde que cada qual apresente elementos funcionais mínimos relativos à sua lógica interna. Mesmo que algumas regras de caráter oficial/formal (número de jogadores, tempo de jogo, tamanho da quadra, etc.) sejam modificadas, a lógica interna continua presente, permitindo o reconhecimento de determinada prática enquanto tal (PARLEBAS, 2001).
} 
competições pedagógicas, nas quais, em linhas gerais é nítida a preocupação com uma participação efetiva de todos os praticantes (e não apenas como "torcedores de luxo" sentados no banco de reservas), a paridade entre os competidores, as adaptações condizentes com as condições de cada faixa etária (por exemplo, diminuição do espaço, tempo e número de competidores, sobretudo nos jogos esportivos coletivos), entre outros.

Siedentop (1987) e Freire (2011), por sua vez, oferecem bases teóricas para organização não apenas de competições pedagógicas, mas também de um processo pedagógico de formação esportiva como um todo, que, por sua vez, determina diretamente a organização de modelos competitivos diferentes do alto rendimento.

Siedentop (1987), ao propor o modelo curricular de ensino esportivo denominado "Sport Education" (Educação Esportiva) $)^{3}$, defende que o processo de EAT deve estar estruturado para gerar competência, literácia (cultura) e entusiasmo esportivo. Para tanto, o autor sugere que os contextos de formação esportiva não devem negar, mas sim, partir da própria competição esportiva, esta também estruturada de maneira pedagógica. Ou seja, o modelo não se restringe à competição, mas sim a utiliza como ponto de partida para toda estruturação do processo de EAT, simulando uma "temporada esportiva". Como explica Graça (2008, p. 28),

Atrai-nos particularmente a ideia de recriar um contexto desportivo autêntico, substituindo as típicas unidades didácticas de curta duração pelo conceito de época desportiva, que congrega a ideia de prática desportiva, com a institucionalização de clubes; com filiação duradoura e competição calendarizada; com a conservação de registros de resultados e estatísticas dos desempenhos individuais e de grupos; com a atribuição de papéis e funções que compõem o envolvimento desportivo, capitães, treinadores, árbitros, directores, jornalistas.

Ressalta-se, assim, que embora o modelo paute-se na criação de condições para participação de todos os praticantes conforme seus interesses e potencialidades, não deixa de adotar critérios objetivos para avaliação do desempenho de todos os praticantes e, em especial dos que atuam enquanto jogadores, sobretudo a partir dos registros/estatísticas de indicadores de jogo.

A proposta de Freire (2011), por sua vez, não parte da competição assim como o modelo de Educação Esportiva, mas baliza-se na ideia de que o processo de formação esportiva, não sendo determinado pelo resultado competitivo, deve ser balizado por quatro princípios pedagógicos ${ }^{4}$ similares aos propostos por Siedentop (1987): ensinar esporte bem, ensinar esporte a todos, ensinar mais do que esporte e ensinar a gostar de esporte. Particularmente em relação à competição, Freire (2011) defende que a avaliação não deve se encontrar na vitória ou derrota, mas sim em critérios relativos ao empenho, à aplicação das habilidades e tomadas de decisão aprendidas/treinadas e ao cumprimento de acordos pré-estabelecidos.

É nessa esteira que construí o presente trabalho, tendo como objetivo apresentar, em forma de uma sistematização de experiência, uma proposta de adaptação pedagógica de competição de basquetebol para crianças e adolescentes que se aproxime dos princípios pedagógicos apresentados por Siedentop (1987) e Freire (2011).

\section{MÉTODOS}

Trata-se de uma sistematização de experiência, que, como propõe Jara Holliday (2006), pauta-se na revisão/avaliação de uma prática em busca de gerar e compartilhar um aprendizado que pode contribuir para fomentar práticas futuras. Importa esclarecer que a experiência ora sistematizada não foi realizada dentro da esfera acadêmica, em forma de projeto de pesquisa ou extensão, tratando-se, na realidade, de uma ação prática a fim de resolver um problema surgido na própria prática.

Tampouco foi elaborada para testar a aplicação dos pressupostos de Siedentop (1987) ou Freire (2011), os quais acabei conhecendo somente anos depois, ao longo de minha trajetória acadêmica. Contudo, justamente por identificar semelhanças entre os objetivos traçados (geração de inclusão, competência e autonomia dos

\footnotetext{
3 Tal modelo tem sido estudado e difundido desde então, como nos exemplos de Siedentop (1992; 1998; 2002), Mesquita e Graça (2006), Graça e Mesquita (2007; 2013), Graça (2008), Luquin, Hastie, Pérez (2011), Campo et al. (2014), Mesquita et al. (2014), Cuevas, García-López e Contreras (2015), Meroño, Calderón e Hastie (2015), Costa e Kravchychyn (2016) e Ginciene e Matthiesen (2017).

${ }^{4}$ No original, o autor refere-se ao futebol. Depois dele, outros autores, como, por exemplo, Santana (2008) e Paes, Montagner e Ferreira (2009), estenderam a interpretação de tais princípios pedagógicos a outras modalidades esportivas e/ou ao esporte como um todo.
} 
jogadores) e a organização da experiência com os eixos/princípios e forma de lidar com a competição no modelo/proposta dos autores é que acreditei que se tratava de uma "boa experiência" a ser compartilhada com os pares.

\section{Cenário da experiência}

A experiência apresentada ocorreu no município de Curitiba, Paraná, no ano de 2008, e foi desenvolvida no contexto de um colégio particular localizado em uma região popular/periférica do município. As equipes com praticantes até 12 anos de idade treinavam três horas por semana, enquanto as equipes com praticantes de 13 a 15 e de 16 a 17 anos de idade treinavam 5 e 7 horas semanais, respectivamente. Embora ofertada por uma instituição privada, a possibilidade de prática era aberta para toda a comunidade.

A participação em competições, contudo, era mitigada pelas condições financeiras disponibilizadas pelo Colégio para tal, de forma que os treinadores precisavam escolher entre campeonatos e categorias possíveis. Comumente participava dos campeonatos federados apenas a equipe com maiores condições de resultados em cada modalidade esportiva ou dentre as modalidades esportivas. Para as demais equipes/categorias, restava a participação em campeonatos menores, menos dispendiosos, ou organizados pelo poder público.

\section{Cuidados éticos}

A participação de todos os participantes da experiência se deu por livre e espontânea vontade e com o consentimento dos pais ou responsáveis, inclusive, confirmada pela assinatura destes na "ficha de inscrição" do praticante para participação nas atividades relativas ao basquetebol (ensino-aprendizagem-treinamento e competições) no Colégio.

\section{RESULTADOS E DISCUSSÃO}

\section{O planejamento e a organização da experiência}

No ano de 2008, a partir de algumas experiências anteriores que se mostraram eficazes como alternativa à carência de recursos para participar de competições "formais", planejei o que denomino aqui de "Campeonato $X^{\prime \prime}$. Se eu conseguisse efetivá-lo na prática, atenderia a três fins: primeiro, seria uma ferramenta pedagógica para geração de inclusão, competência e autonomia dos jogadores, permitindo aos mesmos fazerem o que mais gostavam de fazer em relação ao basquetebol: jogar ${ }^{5}$.

Segundo, seria uma forma de manter os praticantes disputando uma competição anual e motivadora, com participação efetiva de todos e enfrentando desafios de diferentes níveis técnicos, sem que isto gerasse gastos extras para o Colégio. E terceiro, seria um alternativa de competição àquelas em que não podíamos participar (devido ao custo), mas com nível técnico equivalente e que pudesse contribuir para o aprimoramento dos jogadores.

Para tanto, minha primeira e desafiadora decisão foi sobre ter que abrir mão semanalmente de um dia de EAT (que abrangia três equipes e seis faixas etárias), reservando-o ao Campeonato X. Acreditei que a própria participação em jogos completos, mais do que exclusivamente os treinamentos, poderia contribuir para o processo de EAT dos jogadores. Ao mesmo tempo, acreditei que o envolvimento dos mesmos com a autoorganização das equipes e organização do Campeonato X como um todo, como propõe o Siedentop (1987), contribuiria para o aprimoramento de seus conhecimentos sobre o basquetebol.

Dessa forma, acordei com os jogadores que todas as terças-feiras seriam destinadas ao Campeonato $\mathrm{X}$, no período da tarde. A segunda decisão foi em relação à divisão entre faixas etárias. Considerando que

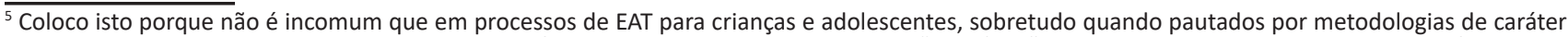
mais tecnicista, treinadores preocupem-se mais em fazer com que os jogadores realizem "exercícios" e atividades de treino em geral do que efetivamente em possibilitar que joguem o jogo formal em si (com regras oficiais ou pequenas adaptações) (GRAÇA, 2008; GRAÇA; MESQUITA, 2013; MESQUISTA; GRAÇA, 2006; SIEDENTOP, 1987).
} 
qualquer tipo de divisão entre crianças e adolescentes sempre abrangerá jogadores mais e menos maduros em uma mesma categoria, optei por uma divisão simples por ano de nascimento. Contudo, diferentemente de categorias federadas, comumente divididas em faixas de dois anos de nascimento (sub-17, sub-15, etc.), optei por fazer com que cada ano de nascimento fosse uma categoria. Sendo assim, a primeira categoria abrangia jogadores que haviam completado ou completariam 12 anos em 2008, e assim por diante, até a categoria de 17 anos. Nenhum jogador em faixa etária diferente da respectiva categoria, mesmo que inferior, poderia compôla.

A decisão seguinte envolveu a quantidade e seleção de equipes em cada categoria. Decidi que cada qual contaria com quatro equipes, sendo: a equipe da faixa etária correspondente em si; a equipe da faixa etária imediatamente inferior; e duas equipes convidadas. A opção por inserir em cada categoria a nossa equipe de faixa etária eminentemente inferior, foi para, além de preencher o número de quatro equipes por categoria, aumentar a quantidade de jogos de cada jogador e possibilitar a todos a experiência de disputar jogos com maior nível técnico. No caso específico de categoria de 12 anos, como não havia jogadores com faixa etária inferior, optei por criar uma equipe com jogadores de 13 anos, mas que ainda eram iniciantes. Esta decisão mostrou-se sensata, pois estes jogadores conseguiam reconhecer que não tinham condições de disputar a categoria de 13 anos (o que foi comprovado pelo fato de terem perdido todos os jogos). Nossa equipe de 17 anos, assim como a de iniciantes de 13 anos, disputou somente uma categoria, mas, em compensação, realizava treinamentos junto à equipe adulta.

Para seleção das equipes convidadas, busquei aquelas que apresentassem um nível técnico próximo ao dos nossos jogadores. A partir da seleção prévia de equipes, ponderei quais seriam os treinadores com perfil mais próximo para compreender e cooperar com os ideais pedagógicos do Campeonato X. Convidei um total de 4 instituições, sendo apenas uma participante de todas as categorias.

Para todos os treinadores foi apresentada a ideia pedagógica do Campeonato $\mathrm{X}$ e esclarecido que, na organização interna de nossas equipes ("da casa") haveria a divisão dos jogadores por ano de nascimento, que poderia ser adotada ou não também por eles na composição de suas equipes. Ao mesmo tempo, foi apresentado o regulamento a eles e à treinadora que trabalhava comigo dirigindo as equipes até 13 anos, para que tecessem sugestões.

Nenhuma sugestão foi realizada e manteve-se o regulamento original, que previa inicialmente a forma de disputa, na qual, em cada categoria haveria disputa de todos contra todos em um único turno e "playoff" final. Cada equipe jogava 3 jogos durante a fase de classificação e mais 2 no playoff (semifinal e final ou disputa de 3 o lugar). No cômputo total, cada equipe disputou 5 jogos, somando um total de 10 jogos por categoria e 60 jogos ao todo pelo Campeonato $X$.

No caso de nossas equipes (exceto a de iniciantes de 13 anos e a de 17 anos), todos os jogadores participaram de 10 jogos, pois que disputavam em duas categorias. Como foram destinados 20 dias ao Campeonato $X$ e cada jogador jogou em apenas 10 deles, em outros 10 acabaram não treinando formalmente. Ainda assim, eles próprios relataram que preferiram abrir mão de alguns dias de EAT para poderem disputar e se envolver com o Campeonato X. Após a organização da forma de disputa, foram tecidas as adaptações pedagógicas às regras formais do basquetebol "oficial", sendo:

- não adoção da regra de 24 segundos. A partir do bom senso, quando o árbitro percebia que alguma equipe estava demorando demais para finalizar, gritava "sete" e contava os segundos até "zero", tendo a equipe que finalizar durante este tempo. Este procedimento foi adotado por acreditar-se que, em categorias formativas é importante que os praticantes tenham um tempo maior para compreender as situações e formular as decisões.

- todos os jogadores deveriam jogar e ficar no banco de reservas, no mínimo, um período completo da partida. Esta regra servia para estimular que todos os jogadores pudessem ter um mínimo de participação no jogo e para que houvesse diferentes formações coletivas, exercício de distintas funções por cada jogador em quadra e consequente ampliação de experiências de jogo.

- as substituições no meio do período apenas foram permitidas quando um jogador se machucava ou saía por excesso de faltas. Esta regra também servia para estimular que todos os jogadores pudessem ter um mínimo de participação no jogo, para gerar segurança de que não seriam substituídos por terem cometido algum erro, como não raro ocorre no basquetebol formal, e para permitir que cada formação coletiva tivesse um tempo mínimo para 
se adaptar ("entrosar") à situação de jogo.

- a duração dos jogos foi de foi de 4 períodos de 10 minutos (8 minutos para categoria de 12 anos) corridos, sendo parado o cronômetro apenas em tempos solicitados pelos treinadores (40 segundos) e no minuto final de cada período, quando de bolas paradas. Com isto buscou-se jogos com menor duração total, diminuindo também o tempo ocioso dos jogadores que aguardavam sua vez de jogar (e garantindo um tempo de bate-bola informal no período em que o ginásio ainda estava disponível, ao final do último jogo). Buscamos também diminuir o desgaste para os jogadores, sobretudo pensando-se nos de menores faixas etárias.

- cada jogador podia fazer um total de três faltas pessoais, sendo eliminado da partida na quarta; e cada equipe podia fazer três faltas coletivas por período de partida, sendo, a partir da quarta, todas punidas com dois lanceslivres para a equipe adversária. Com estas regras buscava-se diminuir a incidências de faltas cometidas ao longo do jogo. Ao mesmo tempo buscava-se que os jogadores aprimorassem as ações de defesa e que ocorresse uma maior incidência de cestas, favorecendo o êxito e a motivação.

- alterações exclusivas para categorias de 12, 13 e 14 anos: a defesa deveria ser obrigatoriamente individual; somente a categoria de 14 anos, e somente no último período de cada partida, estava liberada para realizar qualquer outro tipo de defesa. Com isso buscava-se que o uso da defesa individual estimulasse as capacidades tático-técnicas defensivas básicas de marcação do atacante com e sem bola. A liberdade de escolha da defesa para categoria de 14 anos no último período estava relacionada ao fato de que já compreendiam em maior medida a necessidade de alterações coletivas para reverter ou evitar que um placar fosse revertido (por exemplo, uso de defesas pressionadas na quadra inteira ou de defesas por zona fechadas, respectivamente).

- alterações exclusivas para categoria de 13 anos: uso da bola mirim, respeitando-se as características da faixa etária e o padrão utilizado em âmbito federado;

- alterações exclusivas para categoria de 12 anos (além do menor tempo de jogo): uso da tabela mini e bola mirim, respeitando-se as características da faixa etária e o padrão utilizado em âmbito federado. Outra adaptação foi a não adoção da regra dos 8 segundos, pois considerou-se as possíveis dificuldades em chegar ao ataque, sobretudo em caso de enfrentar-se defesa em quadra inteira. Pensou-se também em garantir um maior tempo para compreensão das situações e tomadas de decisão.

Após o aceite do regulamento pelos treinadores, apresentei-Ihes a tabela de jogos, com duração de seis meses, o que favoreceria a filiação duradoura e competição calendarizada do modelo de Educação Esportiva (GRAÇA, 2008). Eventualmente os jogos eram transferidos de data, desde que antecipadamente solicitado por uma das equipes. A montagem da tabela, em respeito à participação das equipes convidadas, foi dividida em dois grupos, chamados de "amarelo" (categorias de 12, 13 e 14 anos) e "preto" (categorias de 15, 16 e 17 anos). Tais grupos serviam apenas para reunir jogos de jogadores com faixa etária próxima, mas não se tratavam de algum tipo de chaveamento. Em um dia realizavam-se os jogos do grupo amarelo e no outro, do grupo preto, sempre dentro de um tempo total de três horas e meia (três jogos por dia, na ordem crescente de categorias).

As condições de participação para equipes convidadas eram de que tentassem ao máximo respeitar a tabela, de que todos os jogos fossem realizados em nosso ginásio, de que contribuíssem com uma taxa única de $R \$ 10,00$ para ajudar na compra das medalhas e de que, se desejassem, doassem 1 quilo de alimento por jogador inscrito. Os jogos das equipes de cada instituição eram sempre concentrados no mesmo dia, de forma que, em regra, ela precisaria dedicar somente um dia por mês para o Campeonato X (somente a instituição que participou de todas as categorias precisava dedicar dois dias, um para cada grupo).

A arbitragem dos jogos foi feita exclusivamente por mim ou por minha colega treinadora, de forma que cada qual arbitrava os jogos das equipes do colega. Quando os jogos eram entre duas equipes convidas, eu realizava a arbitragem. No início do Campeonato $X$ e antes de cada jogo, explicávamos aos treinadores/ jogadores o caráter pedagógico dos jogos e as dificuldades em arbitrar um jogo sozinho. Nenhum problema de reclamação ou contestação da arbitragem ocorreu durante a competição.

\section{O desenvolvimento da experiência e suas relações com pressupostos de Siedentop (1987) e Freire (2011)}

Em linhas gerais, para organização das nossas equipes, decidi que, sempre que o jogo fosse contra um adversário convidado, eu estaria no banco de reservas realizando orientações (no caso de nossas equipes até 13 anos, isto seria feito pela minha colega treinadora). Quando fosse o caso de um jogo entre duas equipes 
nossas, eu ou minha colega orientaríamos a equipe de menor faixa etária e deixaríamos a mais experiente se auto-organizar. Esta decisão contribuiu sobremaneira para gerar autonomia e conhecimento dos jogadores sobre o basquetebol, pois precisavam refletir sobre a autogestão da equipe (sistema de ataque, de defesa, titulares, reservas, substituições, tempos técnicos, etc.).

Se eu ou minha colega percebíamos que os jogadores estavam entrando em um processo de anarquia, prejudicando sua própria equipe ou dificultando em demasia a atuação da equipe adversária, intervínhamos de alguma maneira, comumente dando alguma dica ou conversando nos intervalos entre os períodos de jogo. As dicas eram no sentido recomendar que mudassem algum jogador, oportunizassem mais tempo de jogo aos "reservas", modificassem algum sistema de jogo, entre outras.

Além do auto gerenciamento, que incumbia aos praticantes o papel de treinadores, também realizavam a função de mesários e analisadores de jogo. Exceto os praticantes de 12 anos, todos participavam do preenchimento da súmula e registro de indicadores de jogo, sempre com supervisão minha. Mesmo quando não havia jogo da respectiva equipe, os jogadores compareciam ao ginásio para envolverem-se com o Campeonato $X$, seja ajudando com os registros, seja para assistir e/ou treinar ou "bater bola" nos momentos de intervalo ou após o encerramento do último jogo.

A súmula e o registro de indicadores de jogo de cada equipe eram feitam sempre em duplas. Um jogador assistia ao jogo e repassava as informações ao outro, que anotava. Os indicadores de jogo foram: arremessos de 2 pontos tentados e convertidos, arremessos de 3 pontos tentados e convertidos, lances livres tentados e convertidos, rebotes defensivos e ofensivos, assistências, roubadas de bola, tocos e faltas cometidas e sofridas. Posteriormente era calculado o total de pontos tentados e feitos, o total de rebotes e o total de indicadores de cada equipe, vez que a anotação era realizada em relação a cada jogador.

Posteriormente eram tabulados por mim e enviados em boletins semanais aos treinadores. Tomei a decisão de computar tais indicadores por várias razões: ajudar os treinadores a compreenderem objetivamente suas respectivas equipes e melhor prepará-las (não apenas para o Campeonato $X$, mas de uma maneira geral); aprimorar o conhecimento e controle de jogo por parte dos próprios jogadores, que, para além de entender a pontuação como um critério individual importante (pois que é o único indicador de jogo que a súmula apresenta, além das faltas cometidas), passavam a compreender que outras ações também eram importantes para o bom desempenho coletivo; e estimular os jogadores a se empenharem ao máximo durante o jogo, conquistando o maior número de indicadores, que seriam premiados ao final.

Ou seja, os indicadores de jogo ofereciam aos jogadores dados objetivos sobre seu desempenho, em acordo ao modelo de Siedentop (1987) e aos critérios de avaliação sugeridos por Freire (2011). O somatório entre a coleta dos indicadores de jogo e as possibilidades de autoavaliação a partir deles contribuía, assim, para desenvolvimento da competência, cultura (literácia) e entusiasmo sobre o basquetebol, conforme os eixos fundamentais do modelo de Educação Esportiva, e contribuía para que todos aprendessem bem, mais do que, e a gostar de basquetebol, consoante os princípios de Freire (2011).

Como forma de valorizar o empenho e a aplicação dos conhecimentos procedimentais previamente aprendidos/treinados, seguindo os pressupostos de avaliação de Freire (2011) e os eixos de Siedentop (1987), um vasto arcabouço de premiações foi desenvolvido, abrangendo a primeira, segunda e terceira equipe melhor classificada em cada categoria e o melhor jogador, melhor defensor, cestinha, passador (maior média de assistências), "reboteiro" (maior mádia de rebotes), "roubador" (maior média de roubadas de bola) e "bloqueador" (maior média de tocos) geral e de cada categoria. No encerramento do Campeonato X foi realizado ainda um torneio de três pontos, dividido em duas categorias (grupo amarelo e grupo preto), sendo premiados os três primeiros de cada qual. Todos os jogadores interessados podiam participar deste torneio.

No total foram distribuídas 325 medalhas dentre um total aproximado de 200 jogadores participantes do Campeonato $X$ (média de 8 a 9 jogadores por equipe). Ou seja, mesmo sem distribuir medalhas pela simples participação no Campeonato $X$, praticamente todos foram premiados e muitos receberam mais de uma medalha. Este procedimento de premiação apresentou-se bastante importante porque manteve a motivação dos jogadores elevada ao longo de todo o Campeonato X e fez com que cada medalha recebida fosse valorizada, pois sabia-se que havia sido conquistada por esforço e mérito e não pela "comoção" dos organizadores. Tal procedimento condiz com a necessidade de autopercepção de competência sugerida por Siedentop (1987) e Freire (2011). O Quadro 1 sintetiza as aproximações entre o Campeonato X e alguns dos pressupostos do 
modelo de Siedentop (1987) e da proposta de Freire (2011).

Ainda que sem uso de algum instrumento objetivo, assim, foi possível identificar uma importante melhora na autonomia, competência, cultura (compreensão sobre o jogo) e entusiasmo dos jogadores em relação ao basquetebol. Os resultados em outras competições, inclusive, mostraram-se superiores aos que ocorriam em anos anteriores. Além disso, os próprios jogadores eram encontrados constantemente planejando estratégias para o Campeonato X do ano seguinte, "apostando" nas premiações coletivas e individuais, e especulando e sugerindo as próximas instituições a serem convidadas. Os laços de amizade entre os jogadores e treinadores intra e inter equipes também aumentou e muitos de nossos jogadores foram convidados para disputar pelas equipes convidadas, competições das quais não participávamos.

A avaliação final dos treinadores foi positiva, sobretudo da treinadora da instituição que participou de todas as categorias. Assim como nós, ela percebeu e relatou significativa melhora em todos os sentidos em seus jogadores (autonomia, competência, conhecimento e entusiasmo). Todos, inclusive, "convidaram-se" para participar novamente nos anos seguintes.

Quadro 1. Relação da experiência sistematizada com os eixos/princípios pedagógicos e visão geral sobre a competição do modelo de Siedentop (1987) e proposta de Freire (2011).

\begin{tabular}{|c|c|c|}
\hline Siec & 11) & X) \\
\hline $\begin{array}{l}\text { xos norteadores } \\
\text { o modelo (formar } \\
\text { raticantes esporti- } \\
\text { amente): } \\
\text { competentes; } \\
\text { cultos; } \\
\text { entusiastas. }\end{array}$ & $\begin{array}{l}\text { Princípios nortea- } \\
\text { dores da proposta } \\
\text { (ensinar): } \\
\text { - esporte e todos; } \\
\text { - esporte bem; } \\
\text { - a gostar de espor- } \\
\text { te; } \\
\text { - mais do que es- } \\
\text { porte. }\end{array}$ & $\begin{array}{l}\text { - a organização das categorias, as regras adaptadas, a tabela de jogos e } \\
\text { a participação dos praticantes na organização do Campeonato poderiam } \\
\text { contribuir para o envolvimento efetivo de todos com o basquetebol; } \\
\text { - a participação e envolvimento com a organização do Campeonato pode- } \\
\text { riam contribuir para o desenvolvimento de gosto (entusiasmo) pela práti- } \\
\text { ca, fortalecendo os vínculos dos praticantes entre si e com o basquetebol; } \\
\text { - a quantidade de jogos, de tempo efetivo de cada jogador no jogo e de } \\
\text { autogestão da equipe, além do registro de indicadores de jogo e da possi- } \\
\text { bilidade de auto-avaliação por meio dos mesmos poderia contribuir para } \\
\text { o desenvolvimento da competência de jogo; } \\
\text { - o respeito às regras de jogo, a responsabilidade com a organização do } \\
\text { Campeonato e as constantes trocas de experiência entre si, com o trei- } \\
\text { nador e com as demais equipes poderiam contribuir para formação dos } \\
\text { praticantes enquanto pessoas/cidadãos, extrapolando os conhecimentos } \\
\text { sobre basquetebol. }\end{array}$ \\
\hline $\begin{array}{l}\text { A competição: } \\
\text { - pauta todo o pro- } \\
\text { cesso de EAT; } \\
\text { - jogadores exercem } \\
\text { diferentes papeis/ } \\
\text { funções; } \\
\text { - desempenho dos } \\
\text { jogadores avaliado } \\
\text { pelo registro de in- } \\
\text { dicadores de jogo. }\end{array}$ & $\begin{array}{l}\text { A competição con- } \\
\text { tribui para avalia- } \\
\text { ção: } \\
\text { - do empenho; } \\
\text { - da aplicação das } \\
\text { habilidades; } \\
\text { - da atenção e to- } \\
\text { madas de decisão; } \\
\text { - do cumprimento } \\
\text { dos acordos. }\end{array}$ & $\begin{array}{l}\text { - praticantes exerceram as funções de jogadores, treinadores, mesários } \\
\text { e analistas; } \\
\text { - avaliação do desempenho dos jogadores foi realizada pelo registro de } \\
\text { indicadores de jogo, além do feedback oferecido pelo treinador e pelo } \\
\text { próprio resultado dos jogos e da competição; } \\
\text { - nível de disciplina e responsabilidade foi elevado, pois a realização e or- } \\
\text { ganização do Campeonato foram acordadas junto aos jogadores, ficando } \\
\text { entendido que era "deles", "para eles" e "por eles"; } \\
\text { - ao final dos jogos "oficiais" de cada dia de Campeonato, havia tempo } \\
\text { remanescente no ginásio para que os praticantes pudessem organizar/ } \\
\text { treinar sua respectiva equipe e/ou, ao menos, fortalecer a aprendizagem/ } \\
\text { treinamento e os vínculos de amizade por meio da prática informal. }\end{array}$ \\
\hline
\end{tabular}

Fonte: Siedentop (1987), Freire (2011) e experiência sistematizada.

Elaboração: o autor.

\section{CONSIDERAÇÕES FINAIS}

As múltiplas situações em que os jogadores se encontraram dentro dos jogos e os múltiplos papeis realizados ao longo do Campeonato X (jogadores, treinadores, mesários, analistas, torcedores), em conjunto aos momentos informais propiciados pelo tempo em que estavam no ginásio são fatores aptos a contribuir 
para sua formação esportiva e pessoal, sem perder de vista a melhora de seu rendimento esportivo.

A constatação de semelhanças aos pressupostos de Siedentop (1987) e Freire (2011) em conjunto à avaliação positiva por parte de todos os participantes são os fatores encorajadores para que eu compreenda a experiência relatada como sendo de sucesso e busque compartilhá-la em âmbito acadêmico, a fim de tentar contribuir para formação de novos profissionais de Educação Física.

Obviamente, a experiência sistematizada apresenta limitações tanto no que diz respeito à sua realização quanto à sua avaliação. No primeiro caso, a partir de conhecimentos adquiridos posteriormente, percebo que - Campeonato $X$ ainda esteve muito próximo do padrão de competições do alto rendimento, sobretudo em relação ao espaço e tempo de jogo e ao número de jogadores. Adaptações nesse sentido, sobretudo para as menores faixas etárias, com número reduzido de jogadores e jogos simultâneos em miniquadras, por exemplo, poderiam contribuir para uma participação mais efetiva.

A avaliação, por sua vez, ficou circunscrita a critérios subjetivos, como a observação e conversas informais, ou a critérios relativos ao resultado competitivo interno ou externo ao Campeonato X. O controle do processo motivacional ou a comparação com um grupo-piloto não participante do Campeonato $\mathrm{X}$, por exemplo, poderiam oferecer subsídios mais concretos para avaliação da efetividade (ou não) do Campeonato $\mathrm{X}$ enquanto competição pedagógica.

\section{REFERÊNCIAS}

CAMPO, G.; GARCÍA LÓPEZ, L.; CHAPARRO JILETE, R.; FERNÁNDEZ SÁNCHEZ, A. Aplicación del modelo de Educación Deportiva en segundo de Educación Primaria. Percepciones del alumnado y el profesorado. Cuadernos de Psicología del Deporte, Murcia, v. 14, n. 2, p. 131-44, 2014.

CUEVAS, R.; GARCÍA-LÓPEZ, L.; CONTRERAS, O. Influencia del modelo de Educación Deportiva en las necesidades psicológicas básicas. Cuadernos de Psicología del Deporte, Murcia, v. 15, n. 2, p. 15562, 2015.

FREIRE, J. Pedagogia do futebol. 3.ed. Campinas: Autores Associados, 2011.

GINCIENE, G.; MATTHIESEN, S. O modelo do Sport Education no ensino do atletismo na escola. Movimento, Porto Alegre, v. 23, n. 2, p. 729-42, 2017.

GRAÇA, A. Modelos e concepções de ensino do jogo. In: TAVARES, F.; GRAÇA, A., GARGANTA, J.; MESQUITA, I. (Org.). Olhares e contextos da performance nos jogos desportivos. Porto: Universidade do Porto, 2008. p. 25-41.

GRACA, A.; MESQUITA, I. A investigação sobre os modelos de ensino dos jogos desportivos. Revista Portuguesa de Ciências do Desporto, Porto, v. 7, n. 3, p. 401-21, 2007.

GRAÇA, A.; MESQUITA, I. Modelos e concepções de ensino dos jogos desportivos. In: TAVARES, F. (Ed.). Jogos desportivos coletivos - ensinar a jogar. Porto: Universidade do Porto, 2013. p. 9-54.

JARA HOLLIDAY, O. Para sistematizar experiências. 2.ed. Brasília: MMA, 2006.

KRAVCHYCHYN, C.; COSTA, L. Esportes coletivos: handebol e basquetebol. Maringá: UniCesumar, 2016.

LUQUIN, A.; HASTIE, P.; PÉREZ, D. El modelo de educación deportiva (sport education model). ¿metodología de enseñanza del nuevo milenio? Revista Española de Educación Física y Deportes, Madrid, v. 63, n. 395, p. 63-79, 2011.

MEROÑO, L.; CALDERÓN, A.; HASTIE, P. Efecto de una intervención basada en el modelo de Educación Deportiva sobre variables psicológicas en nadadores federados. Cuadernos de Psicología del Deporte, Murcia, v. 15, n. 2, p. 35-46, 2015.

MESQUITA, I.; GRAÇA, A.; Modelos de ensino dos jogos desportivos. In: TANI, G.; BENTO, J. O.; PETERSEN, R. D. S. (Org.). Pedagogia do desporto. Rio de Janeiro: Guanabara Koogan, 2006. p. 26983.

MESQUITA, I.; PEREIRA, C.; ARAÚJO, R.; FARIAS, C.; SANTOS, D.; MARQUES, R. Modelo de educação esportiva: da aprendizagem à aplicação. Revista da Educação Física/UEM, Maringá, v. 25, n. 1, p. 1-14, 2014. 
MONTAGNER, P. (Org.). Intervenções pedagógicas no esporte: práticas e experiências. São Paulo: Phorte, 2011.

PAES, R.; MONTAGNER, P.; FERREIRA, H. Pedagogia do esporte: iniciação e treinamento em basquetebol. Rio de Janeiro: Guanabara Koogan, 2009.

PARLEBAS, P. Juegos, deporte y sociedad: léxico de praxiología motriz. Barcelona: Paidotribo, 2001. REVERDITO, R.; SCAGLIA, A.; MONTAGNER, P. (Orgs.). Pedagogia do esporte: aspectos conceituais da competição e estudos aplicados. São Paulo: Phorte, 2013.

SANTANA, W. Futsal: apontamentos pedagógicos na iniciação e na especialização. 2.ed. Campinas: Autores Associados, 2008.

SIEDENTOP, D. Sport education: a retrospective. Journal of Teaching in Physical Education, Birmingham, n. 21, p. 409-418, 2002.

SIEDENTOP, D. The theory and practice of sport education. In: BARRETE, G.; FEINGOLD, R.; REES, R.; PIERÓN, M. (Ed.). Myths, models \& methods in sport pedagogy. Champaign: Human Kinetics, 1987. p. 79-87.

SIEDENTOP, D. Thinking differently about secondary physical education. Journal of Physical Education, Recreation \& Dance, London, v. 63, n. 7, p. 69-77, 1992.

SIEDENTOP, D. What is sport education and how does it work? Journal of Physical Education, Recreation \& Dance, London, v. 69, n. 4, p. 18-20, 1998.

Autor correspondente: Felipe Canan

E-mail: felipe.canan@gmail.com

Recebido em: 16 de outubro de 2017.

Aceito em: 14 de março de 2018. 